\title{
EDITORIAL
}

\section{Lung Cancer Screening Guidelines Implementation in Primary Care: A Call to Action}

\author{
Cbyke A. Doubeni, MD, MPH', \\ Jobn M. Wilkinson, $M D^{1}$ \\ Neil Korsen, $M D, M S^{3}$ \\ David E. Midthun, $M D^{4}$ \\ 'Department of Family Medicine, Mayo Clinic College of Medicine and Science, Rochester, Minnesota \\ ${ }^{2}$ Center for Health Equity and Community Engagement Research, Mayo Clinic College of Medicine and Science, Rochester, Minnesota \\ ${ }^{3}$ Center for Outcomes Research and Evaluation, Maine Medical Center, Portland, Maine \\ ${ }^{4}$ Pulmonary and Critical Care Medicine, Mayo Clinic College of Medicine and Science, Rochester, Minnesota
}

Ann Fam Med 2020;18:196-201. https://doi.org/10.1370/afm.2541.

A man aged 60 years presented to his primary care physician because of a $5-\mathrm{kg}$ unintentional weight loss over 3 months, hemoptysis, and exertional shortness of breath, but no fever. He had smoked 20 to 30 cigarettes a day since his 20 s before quitting a year prior because of health concerns. A chest radiograph and computed tomography $(\mathrm{CT})$ scan showed findings consistent with lung cancer with metastasis and diagnosis was confirmed promptly. For this patient, a rootcause analysis may ask if opportunities at prevention or early detection were missed. ${ }^{1}$ The most effective way to prevent lung cancer is to avoid exposure to carcinogens (tobacco, radon, or particulate matter). ${ }^{2}$ However, in individuals who unfortunately develop lung cancer, early detection is potentially lifesaving.

In this issue of the Annals, Handy and colleagues report on a lung cancer screening (LCS) program in a network of primary care clinicians in a communitybased health system in Portland, Oregon. ${ }^{3}$ The report suggests that delivery of LCS is feasible in community settings and may achieve comparable process outcomes as the controlled settings of clinical trials. ${ }^{3}$ Their program provides a useful framework for the primary care clinician's role and linkages with a mul-

Conflicts of interest: author reports none.

\section{CORRESPONDING AUTHOR}

Chyke A. Doubeni, MD, MPH

Department of Family Medicine

Mayo Clinic College of Medicine and Science

200 First Street SW

Rochester, MN 55905

Doubeni.Chyke@mayo.edu tidisciplinary team to manage abnormal findings as depicted in Figure 1. ${ }^{4}$

Cancers of the lung and bronchus remain the single most common cause of death from cancer in the United States despite steady declines in incidence and mortality over the decades. Lung cancer is projected to cause nearly as many deaths as breast, colorectal, and pancreatic cancers combined in $2020(135,720$ vs 142,940$),{ }^{5,6}$ and African American men have the highest incidence and mortality of any racial or ethnic group. ${ }^{5}$ The 5 -year survival rate during 2010-2016 for people diagnosed with localized-stage disease is $59 \%$ compared with $5.8 \%$ with metastatic disease at the time of diagnosis, and without screening, $51 \%$ of patients present with metastasis. ${ }^{5}$ Feasibility studies at the Mayo Clinic, ${ }^{7}$ and the National Lung Screening Trial (NLST), ${ }^{8}$ provided the evidence for guidelines endorsing LCS in high-risk people (Table 1) ${ }^{9-19}$ In 2013, the American Academy of Family Physicians (AAFP) concluded the evidence "insufficient to recommend for or against" LCS. ${ }^{18}$ The AAFP noted that the NLST was conducted in "medical institutions" with expertise to achieve "low mortality associated with surgical resection of tumors, which may not be reproducible in all settings." Those concerns are acknowledged in all current guidelines. Although other trials, including the Nederlands-Leuvens Longkanker Screenings ONderzoek (NELSON) and the Italian (MILD) trials, have expanded the evidence base, ${ }^{20,21}$ controversy remains about the applicability of the evidence or the ability to have the expertise and other systems needed for LCS in community settings.

Key details of trials results, including absolute risks, provide insights about LCS' potential impact. 
Figure 1. The lung cancer screening process (primary care physician vs subspecialty).

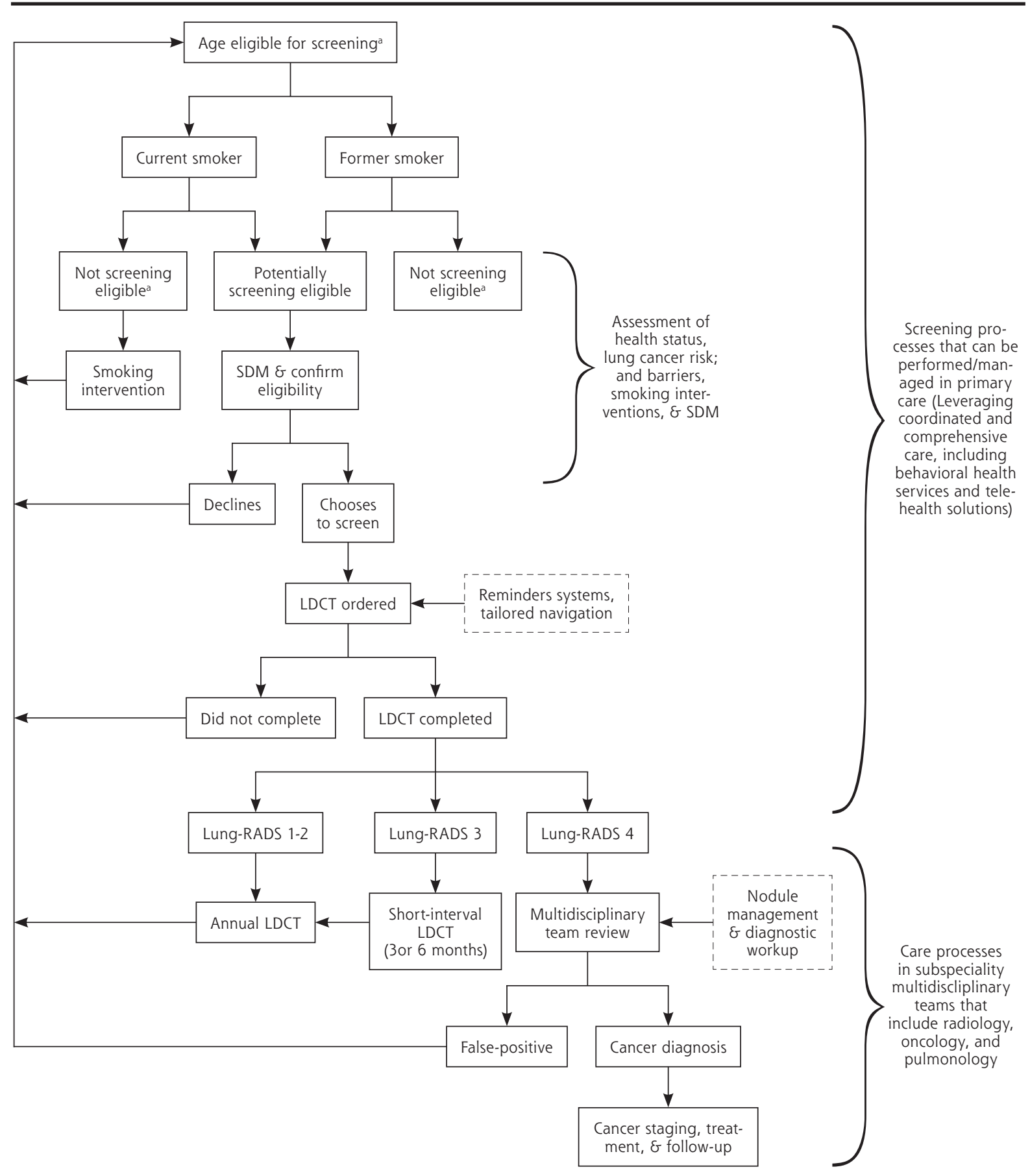

CMS = Centers for Medicare and Medicaid Services; LDCT = low-dose helical computed tomography; Lung-RADS = Lung CT Screening Reporting \& Data System; SDM $=$ shared decision making.

aEligibility for screening is defined primarily on age and smoking criteria, but some risk stratification approaches include other factors not in the US Preventive Service Task Force recommendations, such as radon and occupational exposures and family history. Age criteria vary across guidelines and CMS coverage guidance but is generally in the 50-80 years age group. Patients who are not healthy enough to undergo treatment should not be screened.

The NLST randomized selected high-risk participants aged 55-74 years during 2002-2004 at 33 wellequipped medical centers to receive low-dose helical
CT (LDCT) $(\mathrm{n}=26,722)$ over 3 rounds or chest radiography $(n=26,732)$ and followed them through the end of 2009. ${ }^{8}$ It showed a $20 \%$ lung cancer-specific 
Table 1. Lung Cancer Screening Guidelines Across Organizations

\begin{tabular}{|c|c|c|c|c|c|c|}
\hline Organization & Year & Population & $\begin{array}{l}\text { Endorse } \\
\text { LDCT }\end{array}$ & $\begin{array}{l}\text { Recommended } \\
\text { Setting }\end{array}$ & $\begin{array}{l}\text { Smoking } \\
\text { Cessation }\end{array}$ & SDM $^{\mathrm{a}}$ \\
\hline $\begin{array}{l}\text { National Comprehensive } \\
\text { Cancer Network (NCCN) }\end{array}$ & 2012 & $\begin{array}{l}\text { NLST } \text { criteria }^{8} \text { aged } \geq 50 \text { years with } \\
\geq 20 \text { pack-years plus } 1 \text { risk factor }{ }^{b} \\
\text { and } 1.3 \% \text { PLCO risk }\end{array}$ & Yes & Multidisciplinary team & Yes & Yes \\
\hline $\begin{array}{l}\text { American Association for } \\
\text { Thoracic Surgery }\end{array}$ & 2012 & $\begin{array}{l}\text { Aged } 55-79 \text { or } 50-79 \text { years based on } \\
\text { smoking history and other factors }\end{array}$ & Yes & Multidisciplinary team & Yes & \\
\hline $\begin{array}{l}\text { US Preventive Services Task } \\
\text { Force }^{11}\end{array}$ & 2013 & $\begin{array}{l}\text { Age pack-year and current smoker or } \\
\text { quit } \leq 15 \text { years }\end{array}$ & Yes & $\begin{array}{l}\text { Primary care; NCCN } \\
\text { guidance }\end{array}$ & Yes & Yes \\
\hline American Cancer Society ${ }^{12}$ & 2013 & NLST + imaging/treatment feasible & Yes & NLST-like & & Yes \\
\hline $\begin{array}{l}\text { American College of Chest } \\
\text { Physicians }^{13}\end{array}$ & 2013 & NLST & Yes & NLST-like & & Yes \\
\hline American Lung Association ${ }^{14}$ & 2015 & NLST & Yes & NLST-like & Yes & Yes \\
\hline $\begin{array}{l}\text { Canadian Task Force on Pre- } \\
\text { ventive Health } \text { Care }^{15}\end{array}$ & 2016 & NLST & Yes & $\begin{array}{l}\text { Early diagnosis/ } \\
\text { treatment expertise }\end{array}$ & & Yes \\
\hline CHEST Guideline $^{17}$ & 2018 & 55-77 years/NLST smoking criteria & Yes & & & Yes \\
\hline AAFP $^{18}$ & 2013 & High risk (age and smoking) & $\mathrm{No}^{\mathrm{a}}$ & & Yes & Yes \\
\hline CMS $^{19}$ & 2015 & 55-77 years/NLST smoking criteria & Yes & Provider/facility quality & Yes & Yes \\
\hline \multicolumn{7}{|c|}{$\begin{array}{l}\text { AAFP = American Academy of Family Physicians; CHEST = American College of Chest Physicians; CMS = Centers for Medicare and Medicaid Services; LDCT = low- } \\
\text { dose helical CT; NLST = National Lung Screening Trial; PLCO = Prostate, Lung, Colorectal, and Ovarian Cancer Screening Trial; SDM = shared decision making. }\end{array}$} \\
\hline \multicolumn{7}{|c|}{$\begin{array}{l}\text { "People aged } 55-79 \text { years with } \geq 30 \text { pack-year of smoking history or people aged } 50-79 \text { years with } \geq 20 \text { pack-year of smoking history with personal lung cancer history } \\
\text { or another risk factor such as COPD, environmental or occupational exposure, prior cancer or radiation therapy, genetic predisposition or family history. } \\
\text { d Insufficient evidence to recommend screening. Screening cannot be recommended on the basis of a single study conducted in major medical centers. }\end{array}$} \\
\hline
\end{tabular}

mortality risk reduction (2.47 vs 3.09 deaths per 1,000 person years) in those assigned to LDCT screening after 6.5 years of follow-up. ${ }^{8}$ One subanalysis reported a $39 \%$ mortality risk reduction in African American participants $(\mathrm{n}=2,361$, hazard ration $[\mathrm{HR}]=0.61 ; 95 \%$ CI, 0.37-1.01), suggesting that use of LCS could help reduce health disparities. ${ }^{22}$ The NELSON trial with men $(n=13,195)$ and women $(n=2,594)$ aged 50-74 years showed over 4 rounds of screening a similar effect size ( $24 \%$ mortality risk reduction; 2.50 vs 3.30 deaths per 1,000 person years in screened vs control, respectively) after $\geq 10$ years of follow-up. ${ }^{20}$ About $56 \%$ of lung cancers in the NLST and $68 \%$ in NELSON were detected at stage I/II. ${ }^{8,23}$ Similarly, $70 \%$ of the 95 cancers reported by Handy and colleagues and $86 \%$ of those detected in a United Kingdom lung screening pilot were diagnosed at stage I/II. ${ }^{3,24}$ Those findings suggest that LDCT screening in community settings may produce reasonable outcomes.

It is important, however, to understand why current LCS guidelines include caveats on having appropriate expertise and processes. Screening is highly popular and widely advocated due to its presumed potential to prevent premature death. Screening can, however, create an illusion of benefits even when causing a net harm because of temporal dissonance between harms and benefits. Benefits of LDCT derive from accurate identification of only serious lesions and achieving optimal follow-up and treatment outcomes. The "window of net benefit" for LCS is related to quality of LDCT images and quality of interpretation, disease prevalence in the population, patient health status, and the timeliness, safety, and effectiveness of treatment for abnormal screening results. ${ }^{25}$ Harms due to screening, including death, occur from the test itself or from management of lesions that turned out not to be cancerous (false positives) or are not destined to be fatal during a person's lifetime (overdiagnosis). Therefore, the harms and benefits of LCS vary depending on the population and setting of screening. Given the same health status, people at lower risk may disproportionately experience overdiagnosis and false-positive results. In the NLST, the benefits of LCS were greatest in people in the highest risk strata, but those patients may also have higher prevalence of comorbid conditions and thus a higher complication rate could undermine the benefits. ${ }^{26}$ In NLST, the major complication rate was $14 \% .{ }^{27}$ In Handy and colleagues' report, of 3,402 patients screened, 176 underwent invasive procedures with $23(13 \%)$ procedure-related complications that included 2 deaths. ${ }^{3}$

False-positive rates (FPR), overdiagnosis, and incidental findings contribute to harms. In NLST, the reported FPR was $27.3 \%$ in the first round and, over the 3 rounds of screening, $1.8 \%$ of participants without lung cancer underwent invasive procedures for a posi- 
tive screening result with about 6.5 deaths per 10,000 with false positive results in patients with false-positive results. ${ }^{8}$ The FPR is relatively modest (1.3 to $12.8 \%$ ), however, when based on findings that call for immediate follow-up, ${ }^{23,24,28}$ but the wide range across reports portends similar variation in LCS outcomes in community settings. In the NLST, there were 41 cancers detected per 1,000 people screened, which resulted in 3 averted lung cancer deaths and 4 cancers that may have represented overdiagnosis. ${ }^{27}$ Estimated overdiagnosis rates also vary widely across studies, ${ }^{29-33}$ but was reported as $3.1 \%$ overall during long-term follow-up on the NLST and $8.9 \%$ on the NELSON trial. ${ }^{20,34}$ Another concern is incidental findings, which were reported in $41 \%$ of participants in the Veterans Affairs (VA) program, but clinical implications were unclear. ${ }^{35}$

Therefore, important questions remain about how LCS may be optimally delivered to underserved urban and rural populations. Although Patient Protection and Affordable Care Act provisions allow full coverage of LCS in primary care, it is substantially underutilized with reported prevalence of only about $6 \%$ or less, ${ }^{36-38}$ and primary care clinicians' role seems unclear.

When the program described by Handy and colleagues began in 2013, it was led by an oncologyradiology team that managed all screening processes after a primary care clinician referral. In 2015, primary care clinicians assumed responsibility for shared decision-making and placing LDCT orders. A program coordinator conducted smoking counseling, and eligibility verification. This iteration of the program was supported by automated reminders. A multidisciplinary team from oncology, pulmonology, and thoracic surgery reviewed LDCTs with suspicious or highly suspicious findings and made follow-up recommendations back to the primary care clinician. ${ }^{39}$ The program followed standards for image acquisition, interpretation and reporting, and management of nodules; images were interpreted by radiologists at a tertiary facility. ${ }^{3}$ This strategy conforms with standards recommended in current guidelines and the Centers for Medicare and Medicaid Services (CMS).9-17,19,40

There are some limitations of Handy and colleagues' study, including a non-diverse population with only $1 \%(n=33)$ African American and $<1 \%(n=15)$ American Indian/Alaska Natives (AI/ANs). ${ }^{3}$ It does not provide evidence of the effectiveness of LCS during routine primary care delivery and few details are provided on approaches to promote timely follow-up of abnormal screening results. ${ }^{1,41}$ Information was not provided on the approaches used to systematically identify eligible patients or the number of people who were evaluated or received shared decision making and declined screening or were determined to be ineligible.
Delivery of LCS is hampered by incomplete or inaccurate capture of smoking history and a paucity of valid electronic algorithms for assessing LCS-relevant health status, resulting in a scarcity of reliable estimates of the eligible population and LCS prevalence. Clinical services that are measured, tracked, and incentivized get greater attention and those services which are not incorporated into valid quality metrics, such as National Committee for Quality Assurance (NCQA) performance measures, are often of lesser priority. Integration of LCS into primary care workflow and the development of generally accepted LCS clinical performance metrics (eg, false-positive/recall rates, interval cancers, complications, and 30-day mortality rates), along with incentives, may encourage LCS. Stigma against smoking and lung cancer is widely recognized barrier to care all along the lung cancer care continuum either due to provider bias or patient's perception and anticipation of discrimination. ${ }^{42}$ Digital technologies may improve access to shared decision making, smoking cessation, and nodule management in underserved rural, racial/ ethnic minority, or low-income communities. These issues require study, ideally through a primary care lens.

Family medicine has a critical role in increasing the reach of LCS. Success in tobacco control has been the primary driver of decreasing lung cancer incidence, ${ }^{5}$ and family medicine as a discipline has been a leader in smoking cessation and prevention. The longitudinal, comprehensive, team-based care in primary care, including integrated behavioral health, is an ideal setting to improve access to LCS, particularly for underserved populations. Family doctors have long-term relationships with their patients and can help them consider whether lung cancer screening is right for them. However, obstacles to the adoption of this technology hinder uptake and delivery, and a planned implementation approach is needed to assure optimal benefits. Evidence is needed on whether strategies such as telehealth can enable access to LCS in less-resourced settings and mitigate the effects of some social and structural barriers. ${ }^{10,19}$ The American Academy of Family Physicians (AAFP) can guide the approximately 180,000 family physicians on timeliness, quality, and safety of LCS delivery to build on the gains made from tobacco control. There is no place like family medicine to realize the ideals of lung cancer control, but the engagement of primary care clinicians and support from payers and funding agencies are needed to catalyze the adoption of LCS.

To read or post commentaries in response to this article, see it online at http://www.AnnFamMed.org/content/18/3/196.

Key words: lung cancer screening; primary health care; implementation science; implementation strategies; practice guidelines; Preventive Health Services 
Submitted March 25, 2020; accepted March 25, 2020.

Funding support: C.A.D. was supported in part by the National Cancer Institute of the National Institutes of Health (NIH) under Award Number R01CA213645.

Disclaimer: C.A.D. is a member of the US Preventive Services Task Force (USPSTF), but the content is solely the responsibility of the authors and does not necessarily represent the views and policies of the USPSTF.

\section{References}

1. Doubeni CA, Fedewa SA, Levin TR, et al. Modifiable failures in the colorectal cancer screening process and their association with risk of death. Gastroenterology. 2019;156(1):63-74 e66.

2. US Department of Health and Human Services. The Health Consequences of Smoking-50 Years of Progress: A Report of the Surgeon General. In: The Health Consequences of Smoking-50 Years of Progress: A Report of the Surgeon General. Atlanta, GA: US Department of Health and Human Services, Centers for Disease Control and Prevention, National Center for Chronic Disease Prevention and Health Promotion, Office on Smoking and Health; 2014.

3. Handy JR Jr, Skokan M, Rauch E, et al. Results of lung cancer screening in the community. Ann Fam Med. 2020;18(3):243-249.

4. Rendle KA, Burnett-Hartman AN, Neslund-Dudas C, et al. evaluating lung cancer screening across diverse healthcare systems: a process model from the lung PROSPR consortium. Cancer Prev Res (Phila). 2020;13(2):129-136.

5. SEER Program. SEER*Stat Database: Incidence - SEER 9 Regs Research Data, Nov 2018 Sub (1975-2016) < Katrina/Rita Population Adjustment > - Linked To County Attributes - Total U.S., 1969-2017 Counties, National Cancer Institute, DCCPS, Surveillance Research Program, released April 2019, based on the November 2018 submission. www.seer.cancer.gov.

6. Siegel RL, Miller KD, Jemal A. Cancer statistics, 2020. CA Cancer J Clin. 2020;70(1):7-30.

7. Gillaspie EA, Allen MS. Computed tomographic screening for lung cancer: the Mayo Clinic experience. Thorac Surg Clin. 2015;25(2): 121-127.

8. Aberle DR, Adams AM, Berg CD, et al; National Lung Screening Trial Research Team. Reduced lung-cancer mortality with low-dose computed tomographic screening. N Engl J Med. 2011;365(5): 395-409.

9. Wood DE, Kazerooni EA, Baum SL, et al. Lung cancer screening, version 3.2018, NCCN clinical practice guidelines in oncology. J Natl Compr Canc Netw. 2018;16(4):412-441.

10. Jaklitsch MT, Jacobson FL, Austin JH, et al. The American Association for Thoracic Surgery guidelines for lung cancer screening using low-dose computed tomography scans for lung cancer survivors and other high-risk groups. J Thorac Cardiovasc Surg. 2012;144(1): 33-38.

11. Moyer VA; US Preventive Services Task Force. Screening for lung cancer: US Preventive Services Task Force recommendation statement. Ann Intern Med. 2014;160(5):330-338.

12. Wender R, Fontham ET, Barrera E Jr, et al. American Cancer Society lung cancer screening guidelines. CA Cancer J Clin. 2013;63(2): 107-117.

13. Detterbeck FC, Mazzone PJ, Naidich DP, Bach PB. Screening for lung cancer: diagnosis and management of lung cancer, 3rd ed: American College of Chest Physicians evidence-based clinical practice guidelines. Chest. 2013;143(5 Suppl):e78S-e92S.

14. American Lung Association Lung Cancer Screening Committee. Providing guidance on lung cancer screening to patients and physicians. https://www.lung.org/getmedia/Of9f6821-8817-4444-a647e6ca0c82104c/lung-cancer-screening-report.pdf. Published Apr 2015. Accessed Jan 12, 2020.
15. Canadian Task Force on Preventive Health Care. Recommendations on screening for lung cancer. CMAJ. 2016;188(6):425-432.

16. Oudkerk M, Devaraj A, Vliegenthart R, et al. European position statement on lung cancer screening. Lancet Oncol. 2017;18(12): e754-e766.

17. Mazzone PJ, Silvestri GA, Patel S, et al. Screening for lung cancer: CHEST guideline and expert panel report. Chest. 2018;153(4): 954-985.

18. American Academy of Family Physicians. Clinical Preventive Service recommendation: lung cancer. http://www.aafp.org/patient-care/ clinical-recommendations/all/lung-cancer.html. Published 2013. Accessed Jan 12, 2020.

19. Centers for Medicare and Medicaid Services. National Coverage Determination (NCD) for Lung Cancer Screening with Low Dose Computed Tomography (LDCT) (210.14). https://www.cms.gov/medicarecoverage-database/details/ncd-details.aspx?NCDId=364Encdver $=1 \varepsilon$ $\mathrm{bc}=\mathrm{AAAAQAAAAAAAE}$. Published 2015. Accessed Jan 12, 2020.

20. de Koning $\mathrm{H}$ J, van der Aalst CM, de Jong PA, et al. Reduced lungcancer mortality with volume $\mathrm{CT}$ screening in a randomized trial. N Engl J Med. 2020;382(6):503-513.

21. Pastorino $U$, Silva M, Sestini S, et al. Prolonged lung cancer screening reduced 10-year mortality in the MILD trial: new confirmation of lung cancer screening efficacy. Ann Oncol. 2019;30(7):1162-1169.

22. Tanner NT, Gebregziabher M, Hughes Halbert C, Payne E, Egede LE, Silvestri GA. Racial differences in outcomes within the national lung screening trial. Implications for widespread implementation. Am J Respir Crit Care Med. 2015;192(2):200-208.

23. Horeweg $N$, Scholten ET, de Jong PA, et al. Detection of lung cancer through low-dose (T screening (NELSON): a prespecified analysis of screening test performance and interval cancers. Lancet Oncol. 2014;15(12):1342-1350.

24. Field JK, Duffy SW, Baldwin DR, et al. UK Lung Cancer RCT Pilot Screening Trial: baseline findings from the screening arm provide evidence for the potential implementation of lung cancer screening. Thorax. 2016;71(2):161-170.

25. Sawaya GF, Guirguis-Blake J, LeFevre M, Harris R, Petitti D, US Preventive Services Task Force. Update on the methods of the U.S. Preventive Services Task Force: estimating certainty and magnitude of net benefit. Ann Intern Med. 2007;147(12):871-875.

26. Kovalchik SA, Tammemagi M, Berg CD, et al. Targeting of low-dose CT screening according to the risk of lung-cancer death. $N$ Engl J Med. 2013;369(3):245-254.

27. Robbins HA, Callister M, Sasieni $P$, et al. Benefits and harms in the National Lung Screening Trial: expected outcomes with a modern management protocol. Lancet Respir Med. 2019;7(8):655-656.

28. Pinsky PF, Gierada DS, Black W, et al. Performance of Lung-RADS in the National Lung Screening Trial: a retrospective assessment. Ann Intern Med. 2015;162(7):485-491.

29. Heleno B, Siersma V, Brodersen J. Estimation of overdiagnosis of lung cancer in low-dose computed tomography screening: a secondary analysis of the danish lung cancer screening trial. JAMA Intern Med. 2018;178(10):1420-1422.

30. Wille MM, Dirksen A, Ashraf $\mathrm{H}$, et al. Results of the randomized Danish lung cancer screening trial with focus on high-risk profiling. Am J Respir Crit Care Med. 2016;193(5):542-551.

31. Patz EF Jr, Pinsky P, Gatsonis C, et al; NLST Overdiagnosis Manuscript Writing Team. Overdiagnosis in low-dose computed tomography screening for lung cancer. JAMA Intern Med. 2014;174(2): 269-274.

32. Veronesi G, Maisonneuve P, Bellomi M, et al. Estimating overdiagnosis in low-dose computed tomography screening for lung cancer: a cohort study. Ann Intern Med. 2012;157(11):776-784.

33. Marcus PM, Bergstralh EJ, Zweig MH, Harris A, Offord KP, Fontana RS. Extended lung cancer incidence follow-up in the Mayo Lung Project and overdiagnosis. J Natl Cancer Inst. 2006;98(11):748-756. 
34. National Lung Screening Trial Research Team. Lung cancer incidence and mortality with extended follow-up in the national lung screening trial. J Thorac Oncol. 2019;14(10):1732-1742.

35. Kinsinger LS, Anderson C, Kim J, et al. Implementation of lung cancer screening in the Veterans Health Administration. JAMA Intern Med. 2017;177(3):399-406.

36. Jemal A, Fedewa SA. Lung cancer screening with low-dose computed tomography in the United States-2010 to 2015. JAMA Oncol. 2017;3(9):1278-1281.

37. Pham D, Bhandari S, Pinkston C, Oechsli M, Kloecker G. Lung Cancer screening registry reveals low-dose $C T$ screening remains heavily underutilized. Clin Lung Cancer. 2019;S1525-7304(19)30260-8.

38. Huo J, Shen C, Volk RJ, Shih YT. Use of CT and chest radiography for lung cancer screening before and after publication of screening guidelines: intended and unintended uptake. JAMA Intern Med. 2017;177(3):439-441.
39. American College of Radiology. Lung CT screening reporting and data system (Lung-RADS) version 1.1. https://www.acr.org/ClinicalResources/Reporting-and-Data-Systems/Lung-Rads. Accessed Jan 12, 2020.

40. Wiener RS, Gould MK, Arenberg DA, et al; ATS/ACCP Committee on Low-Dose CT Lung Cancer Screening in Clinical Practice. An official American Thoracic Society/American College of Chest Physicians policy statement: implementation of low-dose computed tomography lung cancer screening programs in clinical practice. Am J Respir Crit Care Med. 2015;192(7):881-891.

41. Doubeni CA, Gabler NB, Wheeler CM, et al. Timely follow-up of positive cancer screening results: A systematic review and recommendations from the PROSPR Consortium. CA Cancer J Clin. 2018; 68(3):199-216.

42. Hamann HA, Ver Hoeve ES, Carter-Harris L, Studts JL, Ostroff JS. Multilevel opportunities to address lung cancer stigma across the cancer control continuum. J Thorac Oncol. 2018;13(8):1062-1075.

\section{CORRECTION}

Ann Fam Med 2020;18:201. https://doi.org/10.1370/afm.2532.

In the reference section of Gabison JG. Implications of the FAST protocol beyond spirituality. Ann Fam Med. 2020;18:98-99, the authors for reference \#1 were listed as, "Lee JY, Khoo Z, See Toh W, et al." when they should have been listed as, "Lum Z, Khoo Z, See Toh W, et al." The publisher regrets the error. 